\title{
CLINICAL CHARACTERISTICS IN SUBCORTICAL ISCHEMIC WHITE MATTER DISEASE
}

\author{
Gilberto Sousa Alves', Carlos Eduardo de Oliveira Alves', Maria Elisa de Oliveira Lanna', \\ Letice Ericeira-Valente ${ }^{7}$, Felipe Kenji Sudo ${ }^{7}$, Denise Moreira ${ }^{2,4}$, Eliasz Engelhardt ${ }^{2}$, Jerson Laks ${ }^{1,3}$
}

\begin{abstract}
Background: Vascular white matter lesions (WML) represent one of the main neuroimage findings in individuals older than 65 years and its clinical significance is still partially understood. Objective: To describe and analyze the clinical profile of a high severity sample with WML focusing on the frontal executive control. Method: Outpatients $(n=20)$ with high severity WML evaluated with magnetic resonance imaging were selected using the Fazekas scale. Results: Most patients ( $n=17 ; 85 \%)$ presented an altered Trail Making Test ratio (section $\mathrm{B} /$ section $\mathrm{A}$ ); on verbal fluency, 15 individuals (75\%) performed below the cutoff score. Apathy (5.9 \pm 4.65$)$ and depression (3.05 \pm 3.67$)$ were frequent as assessed by the Neuropsychiatric Inventory. The impairment in functional activities strongly correlated with apathy $(r=0.814, p<0.001)$ and verbal fluency $(r=0.744, p<0.001)$. Conclusion: Executive dysfunction, apathy, and ratio depression were the main characteristics found. Extension of WML may have distinct impact on the clinical picture, but further studies with methodological adjustments are necessary to provide more definitive conclusions.
\end{abstract}

KEY WORDS: neuropsychology, cognition, behavior, function, vascular dementia, white matter lesions.

\begin{abstract}
Características clínicas na doença isquêmica da substância branca subcortical
Resumo - Fundamento: Lesões vasculares em substância branca (LSB) são um dos principais achados de neuroimagem em indivíduos acima de 65 anos e sua importância em termos clínicos é ainda parcialmente conhecida. Objetivo: Descrever e analisar o perfil clínico de amostra com LSB grave enfocando as alterações do controle executivo frontal. Método: Pacientes ambulatoriais $(n=20)$ avaliados pela ressonância nuclear magnética e com maior proporção de LSB foram selecionados através da escala de Fazekas. Resultados: A maioria dos pacientes ( $n=17 ; 85 \%$ ) apresentou alteração na proporção teste das trilhas (seção $B / A$ ); na fluência verbal, 15 indivíduos (75\%) apresentaram desempenho abaixo do ponto de corte. Apatia $(5,9 \pm 4,65)$ e depressão $(3,05 \pm 3,67)$ foram freqüentes na avaliação pelo Inventário Neuropsiquiátrico. O prejuízo nas atividades funcionais correlacionou-se fortemente à apatia $(r=0,814, p<0,001)$ e à fluência verbal $(r=0,744$, $\mathrm{p}<0,001)$. Conclusão: Disfunção executiva, apatia e depressão foram as principais características encontradas. A extensão e localização das LSB parecem exercer um impacto distinto nas manifestações clínicas, porém estudos futuros com ajustes metodológicos são necessários para conclusões mais definitivas.
\end{abstract}

PALAVRAS-CHAVE: neuropsicologia, cognição, comportamento, função, demência vascular, lesões de substância branca.

Cerebrovascular disease is a relatively common condition and can contribute to cognitive decline in old age ${ }^{1-3}$. Subcortical hyperintensities due to vascular lesions are the most frequent neuroimage findings on magnetic resonance image (MRI) in the majority of individuals older than 65 years ${ }^{4}$. Among the etiologies of vascular impairment, small vessel disease plays a leading role and can be visualized as a lacunar state or as white matter lesions
(WML). WML can involve periventricular and deep subcortical regions and are consequent to partial occlusion of arterioles, generally due to arteriolosclerosis, constituting a picture of subcortical ischemic vascular disease $(S I V D)^{2}$. Those lesions are strongly associated to age and other risk factors, such as arterial hypertension, diabetes mellitus, dyslipidemia, coronary artery disease, smoking, among many others ${ }^{1}$.

'Universidade Federal do Rio de Janeiro, Instituto de Psiquiatria, Rio de Janeiro RJ, Brazil; '2Universidade Federal do Rio de Janeiro, Instituto de Neurologia Deolindo Couto, Rio de Janeiro RJ, Brazil; ' ${ }^{3}$ niversidade do Estado Rio de Janeiro, Rio de Janeiro RJ, Brazil; ${ }^{4} \mathrm{Hospital}$ Pró-Cardiaco, Rio de Janeiro RJ, Brazil.

Received 4 September 2008, received in final form 19 November 2008. Accepted 10 February 2009.

Dr. Gilberto Sousa Alves - Rua Otaviano Hudson 16/608 - 22030-030 Rio de Janeiro RJ - Brasil. E-mail: gsalves123@hotmail.com 
There is crescent evidence associating the presence of WML with a sort of clinical features, including memory impairment, executive dysfunction ${ }^{4}$, apathy, loss of initiative, abulia and depressive symptoms ${ }^{5}$. However, its clinical significance is still partially understood. Most of brain imaging studies have demonstrated a relation of WML and the degree of cognitive losses ${ }^{4}$ and behavior disturbances', although the absence of such associations have also been reported ${ }^{6}$. Other important aspects such as the threshold of WML needed to generate clinical outcomes and the natural course of WML in normal aging and cognitive decline are still in debate.

This study aims at describing the socio-demographic and the clinical profile of a patient sample selected according to the severity of WML (hyperintensities on brain $M R$ ), examining the association of WML, cognitive performance, behavioral disturbances, and functional status.

\section{METHOD}

\section{Sample selection}

This cross-sectional study included a consecutive series of 55 individuals of an outpatient clinic examined from January 2006 to December 2007. Patients with multiple risk factors for cerebrovascular disease (CVD), with or without documented history of stroke and varied degrees of cognitive decline were submitted to a comprehensive clinical neurological, psychiatric, and neuropsychological evaluation. Diagnosis of mild cognitive impairment was established according to Petersen criteria ${ }^{7}$, whereas NINDS-AIREN and DSM-IV criteria were adopted for diagnosing vascular and mixed dementia. Exclusion criteria included major psychiatric disorder, schooling less than four years, motor deficits in dominant hand and sensorial difficulties.

Brain magnetic resonance image was assessed by a neurologist (EE) and a radiologist (DM) who were blind to any information regarding the clinical condition of the patients. Only patients with the highest severity of subcortical lesions $(n=20)$ were selected for the present study. This study was approved by the local Ethics Committee and all the participants have signed a written consent, after receiving complete explanation about the study.

Clinical and functional assessment

Risk factors associated to CVD were investigated by clinical history and the use of Hachinski scale ${ }^{8}$, which assesses previous episodes of stroke, hypertension, atherosclerosis, depression symptoms and physical neurological features. Clinical stage of cognitive impairment was established using the Brazilian validated version of the Clinical Dementia Rating (CDR) scale ${ }^{9,10}$, which ranges from zero (absence of clinical impairment) to three (severe dementia).

Depressive symptoms and behavior changes such as agitation and delusions were assessed by Brazilian validated version of the Cornell depression scale $e^{11,12}$ and by the Neuropsychiatric Inventory (NPI) ${ }^{13,14}$, respectively. The former is an instrument designed to rate depression symptoms in demented patients, and the latter is comprised by 12 behavior items, including delusions, hallucinations, irritability, loss of inhibition, agitation, anxiety, depression, euphoria, apathy, psychomotor, sleep and eating disorders. The level of autonomy for activities of daily living were evaluated with the Functional Activities Questionnaire (FAQ) ${ }^{15}$, rated on a seven-point scale.

\section{Neuropsychological assessment}

The global cognitive performance was assessed by the MiniMental State Examination (MMSE) ${ }^{16}$ and the $\mathrm{CAMCOG}^{17}$. CAMCOG provides a wider analysis of the cognitive domains (memory, orientation, attention, concentration, language, calculation and praxis) with a cutoff score for dementia according to the education level. Aspects of executive function were analyzed using three instruments: Trail Making Test (TMT) A and B forms (time in seconds taken to perform each section) ${ }^{18}$ to assess planning abilities, auto-regulation, fine motor coordination, and im-
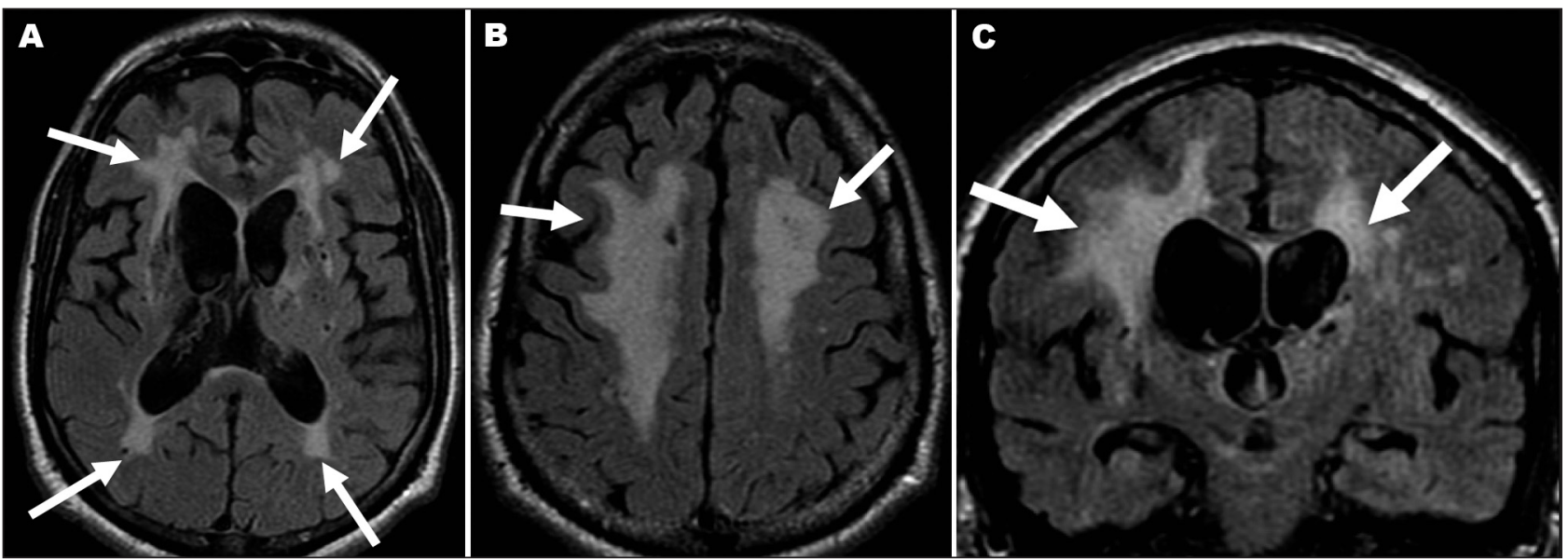

Fig 1. Flair MRI of a patient with higher score in Fazekas scale; white matter lesions (WML) are shown by arrows: [A] periventricular WML affecting anterior and posterior horns, bilaterally (axial section); diffuse ([B] axial section) and deep WML ([C] coronal section. Courtesy of Hospital Pró-Cardíaco, RJ. 
Table 1. Demographic variables and associated risk factors.

\begin{tabular}{lcc}
\hline & $(\%)$ & $\mathrm{N}$ \\
\hline Sex & & \\
$\quad$ Male & $25 \%$ & 5 \\
$\quad$ Female & $75 \%$ & 15 \\
Arterial hypertension & $100 \%$ & 20 \\
Diabetes mellitus & $15 \%$ & 3 \\
Smoking & $30 \%$ & 6 \\
Alcohol consumption & $5 \%$ & 1 \\
History of heart disease & $0 \%$ & 0 \\
History of documented stroke & $30 \%$ & 6 \\
\hline
\end{tabular}

Table 2. Demographic and clinical characteristics of the sample $(n=20)$.

\begin{tabular}{lcc}
\hline & Mean (SD) & range \\
\hline Age & $75.35(7.31)$ & $60-86$ \\
Education & $7.4(4.84)$ & $0-17$ \\
Hachinski & $8.45(3.86)$ & $2-16$ \\
MMSE & $21(5.70)$ & $9-29$ \\
Verbal fluency & $8.75(5.03)$ & $0-20$ \\
CAMCOG & $63.40(19.47)$ & $27-91$ \\
TMT A & $225.30(261.90)$ & $40-1125$ \\
TMT B & $666.25(787.21)$ & $120-3375$ \\
NPI & $19.95(15.20)$ & $0-53$ \\
Cornell & $7.95(5.85)$ & $0-22$ \\
FAQ & $11.40(10.14)$ & $0-30$
\end{tabular}

MMSE: Mini-Mental State Exam; NPI: Neuropsychiatric Inventory; TMT A: Trail Making Test A; TMT B: Trail Making Test B; FAQ: Functional Activities Questionnaire.

pulse control; verbal fluency (number of animal names generated in one minute), and a modified Porteus Mazes test ${ }^{19}$ to assess planning capacity, anticipation, and impulse control. The following values and references were adopted as measures to determine abnormality: percentiles for each form of the TMT, and
TMTB/TMTA ratio $\geq 3$; cutoff points for verbal fluency proposed by Brucki ${ }^{20}$, according to schooling; and a maximum of three errors in the Porteus test.

\section{Lesions quantification in neuroimage}

The MRI was performed with a 1.5 T Signa Horizon scanner (General Electric, Milwaukee, WI, USA). Diffuse subcortical white matter lesions were quantified using FLAIR weighted images and rated by Fazekas et al. scale ${ }^{21}$, complemented by an evaluation of the percentual extent of the WML. Images were visually assessed by two investigators (EE, DM), both blinded to clinical and functional data and the scoring was obtained by consensus. The selected patients presented a Fazekas score $=6$, with white matter legions ranging between 25 and over $75 \%$ (Fig 1). The Fazekas scale is a visual assessment of periventricular ( 0 to 3 points), and centrum semiovale ( 0 to 3 points) white matter changes, in a total of 0 to 6 points range $e^{21}$.

\section{Statistics}

Age, years of education, severity of dementia, behavior outcomes, cognitive, and functional performance were described by using mean (M) and standard deviation (SD). Correlations between clinical and functional data were conducted with Spearman coefficient. The adopted level of significance was $5 \%$. SPSS for Windows, version 15.0 was used as the statistic package.

\section{RESULTS}

The patients were mainly female (Table 1) with a mean age $75.7 \pm 7.3$ years and mean schooling $7.4 \pm 4.8$ years. The clinical diagnosis comprised mild cognitive impairment $(n=6)$, vascular dementia $(n=7)$, and mixed dementia $(n=7)$. According to the CDR scale, six of the patients had questionable dementia ( $C D R=0.5$ ), eleven were in a mild stage of dementia ( $C D R=1)$, two presented moderate dementia $(C D R=2)$, and only one patient had severe dementia $(C D R=3)$. The neurological examination revealed changes in $95 \%$ of the sample $(n=19)$, namely in pyramidal reflexes and balance $(n=12 ; 60 \%)$, and in gait and urinary control $(n=5 ; 25 \%)$. Other demographic and clinical characteristics of the sample are depicted on Table 2.

Table 3. Correlations among performance in cognitive tasks, presence of vascular risk factors (Hachinski score), behavioral disorders (NPI), depression (Cornell) and functional impairment (FAQ), using Spearman coefficient.

\begin{tabular}{lcccccc}
\hline & Age & Education & Hachinski & NPI & Cornell & FAQ \\
\hline MMSE & -0.196 & 0.357 & $-0.543^{*}$ & $-0.633^{* *}$ & -0.398 & $-0.770^{* *}$ \\
Verbal Fluency & -0.374 & -0.285 & -0.417 & $-0.620^{* *}$ & -0.324 & $-0.744^{* *}$ \\
CAMCOG & -0.283 & $0.478^{*}$ & $-0.476^{*}$ & $-0.512^{*}$ & -0.301 & $-0.674^{* *}$ \\
TMT A & 0.169 & $-0.474^{*}$ & 0.272 & 0.419 & 0.228 & $0.479^{*}$ \\
TMT B & 0.127 & $-0.467^{*}$ & 0.299 & $0.446^{*}$ & 0.262 & $0.486^{*}$ \\
Porteus & 0.162 & $-0.481^{*}$ & 0.389 & 0.094 & 0.123 & 0.409 \\
\hline
\end{tabular}

${ }^{*} \mathrm{p}<0.05 ;{ }^{* *} \mathrm{p}<0.01$; MMSE: Mini-Mental State Exam; TMT: Trail Making Test. 


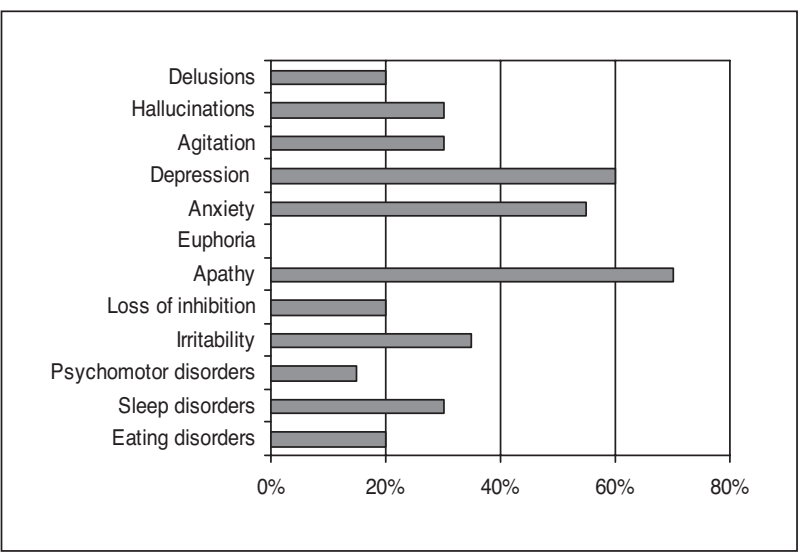

Fig 2. Neuropsychiatric symptoms found in the sample (NPI).

Cognitive performance was affected by age and schooling, as shown in Table 3. The majority of patients presented an altered TMTB/TMTA ratio $(n=17 ; 85 \%)$, and performed equal or bellow the $25^{\text {th }}$ percentile, in both TMT A $(n=15 ; 75 \%)$ and $B(n=16 ; 80 \%)$. Also, most patients ( $n=15 ; 75 \%$ ) showed a verbal fluency below a proposed cutoff score in a Brazilian sample ${ }^{20}$. On the other hand, only 8 individuals (40\%) presented 3 errors in Porteus test. Executive function tasks showed a moderate to strong correlation with ADL (Table 3).

The occurrence of neuropsychiatric features is showed in Figure 2. Apathy and depression were the most common symptoms observed in the NPI scores ([apathy $n=14$; score $=59 \pm 4.65$ ] [depression $n=12$, score $=3.05 \pm 3.66]$ ]), followed by anxiety ( $n=11$; score $=2.9 \pm 3.33$ ). Some patients showed both symptoms of depression and anxiety. As expected, the severity of apathy strongly correlated with the impairment in $A D L(r=0.814, p<0.001)$.

\section{DISCUSSION}

Executive dysfunction, apathy, and depression were the main cognitive and behavioral findings in our sample. Disexecutive syndrome may present as a loss of planning ability and execution of a task, through an appropriate sequence of actions and with error monitoring ${ }^{3}$. It is considered one of the core aspects of SIVD and can be one of the earliest features of this disease ${ }^{3}$. Executive dysfunction has been proposed as one important marker in differential diagnosis among other causes of cognitive decline, such as AD and FTD ${ }^{22}$. The strong correlation found in the current study between executive dysfunction and impaired activities in daily living is in consonance with previous literature ${ }^{23}$. Individuals with executive dysfunction may have difficulties performing complex activities such as medicine and financial management, which requires goal directed behavior, organization of an action and behavioral persistence. On the other hand, impulsiv- ity, loss of inhibition, and personality changes were rarely observed in our sample. Although frequently found in SIVD, there is evidence of a distinct disconnection syndrome leading to such pattern of features, different from that typically presented in executive dysfunction. While fibers connecting limbic and paralimbic areas, including the orbitofrontal cortex, seem to be interrupted in most of the behavioral syndromes, basal ganglia-thalamocortical connections with the prefrontal dorsolateral cortex, are likely affected in executive dysfunction ${ }^{2}$. The discrimination between the two subtypes of clinical presentation can be further detailed by neuropsychological evaluation, with special importance for diagnosis and cognitive rehabilitation approach. Late onset depressive symptoms and lack of motivation are also largely described in vascular patients and can be strongly associated to subcortical $\mathrm{WML}^{24}$. Possibly, interruption of neuronal loops that connect basal ganglia, thalamus and limbic areas may play a role in the etiology of these manifestations ${ }^{25,26}$. Taken together, the co-existence of white matter lesions, executive dysfunction, apathy and depression underlines frontal lobe syndrome as the central characteristic of SIVD ${ }^{5,27}$. In terms of clinical picture and medical intervention, this association may represent a longer duration and greater severity of affective symptoms and also a worse response to antidepressive treatment ${ }^{24}$.

Although all patients selected for the present study presented severe WML, six of them had no diagnosis of dementia ( $C D R=0.5)$. Even in the absence of coexisting brain lesions, a higher intensity of subcortical disease does not necessarily represent a greater impact on cognitive function. This evidence is supported by community investigations such as the Framingham study, that found a proportion of healthy individuals (up to 10 percent) presenting unexpected brain ischemic lesions ${ }^{28}$. In contrast, the association between localization of WML and strategic points of cholinergic pathways affected in vascular disease may influence in clinical presentation ${ }^{29}$. Moreover, some studies demonstrated that periventricular and diffuse white matter lesions affect cognitive functions in different degrees, with the former being more associated with global cognitive impairment ${ }^{30}$ whereas the latter may also be related to motor disturbances, such as gait disorders $^{31}$. Thus, more studies assessing specific brain neuronal circuits which suffer interruption are needed to better clarify the association between anatomical lesions and clinical manifestations in SIVD.

Together with apathy, some neurological disturbances found in our sample - such as gait disorders and loss of urinary control - are considered subacute manifestations of SIVD. Most patients present a gradual course of impairment in volitional and physical features for a long period, with milder symptoms being neglected or poorly 
recognized by relatives and clinicians. More recent studies have highlighted the clinical significance of such manifestations, by reporting a predictive value of long term neurological features (mainly parkinsonism) and apathy severity on the later onset of non-Alzheimer dementia ${ }^{27}$.

The most important methodological strength of the current study is that we started from the radiological diagnosis of the sample. The white matter hyperintensities may represent an important finding which may lead to clinically relevant questions. Firstly, it should draw the attention to typical profiles of cognitive, behavioral and functional features frequently found in vascular disease. Secondly, when combined to clinical data, it allows an earlier diagnosis of SIVD and provides more effective interventions focused on the control of concurrent risk factors (hypertension, diabetes, and smoking), which can contribute to the progression of the disease'. Finally, the presence of such lesions may represent a possible biological marker for conversion to dementia, mainly in groups with nonamnestic mild cognitive impairment, as investigated by recent studies ${ }^{32,33}$. In fact, one article ${ }^{32}$ showed an increased rate of cognitive decline associated with periventricular WML, independently of $\mathrm{MCl}$ subtype, vascular risk factor, and temporal lobe atrophy. Another study ${ }^{33}$ concluded that a large amount of hyperintensities in the periventricular and deep white matter were independent variables for prediction of vascular and mixed dementia over the years.

Some limitations of our study must be taken into account. Some variables that interact with WML, such as global cortical atrophy, mesial temporal atrophy and strategic infarcts were not examined. Previous literature reported an independent association of these measures and executive dysfunction ${ }^{34}$. Thus, the adoption of more than one quantitative rating scale may be considered for future studies, although it is known that most of these instruments are seldom interchangeable and their combined use can lead to greater heterogeneity in the scores and possible reliability biases. Another limitation is the absence of control groups (e.g., AD, healthy controls) which also restricted the investigation on differential diagnosis and the correlation between neuroimage and clinical data.

In conclusion, our study could verify a typical pattern of frontal executive impairment in patients with wide diffuse white matter disease. It seems that the subcortical hyperintensities are associated both to cognitive decline and behavior disorders, as shown in other studies. Localization of these lesions and concurrent brain lesions may have an additional influence on clinical and functional characteristics of SIVD.

\section{REFERENCES}

1. O’Brien JT. Vascular cognitive impairment. Am J Geriatr Psychiatry 2006;14:724-733.
2. Román GC, Erkinjuntti T, Wallin A, Pantoni L, Chui HC. Subcortical ischaemic vascular dementia. Lancet Neurol 2002;1:426-436.

3. Engelhardt E, Laks J, Cavalcanti JLS, Moreira DM, Madalen C. Demência vascular. Rev Bras Neurol 2004;40:5-25.

4. Paul RH, Haque O, Gunstad J, et al. Subcortical hyperintensities impact cognitive function among a select subset of healthy elderly. Arch Clin Neuropsychol 2005;20:697-704.

5. Aharon-Peretz J, Kliot D, Tomer R. Behavioral differences between white matter lacunar dementia and Alzheimer's disease: a comparison on the neuropsychiatric inventory. Dement Geriatr Cogn Disord 2000;11:294-298.

6. Sachdev P, Wen W, Chen X, Brodaty H. Progression of white matter hyperintensities in elderly individuals over 3 years. Neurology 2007;68:214-222.

7. Petersen RC, Smith GE, Waring SC, Ivnik RJ, Tangalos EG, Kokmen E. Mild cognitive impairment: clinical characterization and outcome. Arch Neurol 1999;56:303-308.

8. Hachinski VC, Iliff LD, Zilhka E, et al. Cerebral blood flow in dementia. Arch Neurol 1975;32:632-637.

9. Chaves Ml, Camozzato Al, Godinho C, et al. Validity of the Clinical Dementia Rating scale for the detection and staging of dementia in Brazilian patients. Alzheimer Dis Assoc Disord 2007;21:210-217.

10. Hughes CP, Berg L, Danziger WL, et al. A new clinical scale for the staging of dementia. Br J Psychiatry 1982;140:566-572.

11. Carthery-Goulart MT, Areza-Fegyveres R, Schultz R, et al. Brazilian version of the Cornell depression scale in dementia. Arq Neuropsiquiatr 2007;65:912-915.

12. Alexopoulos GS, Abrams RC, Young RC, Shamoian CA. Cornell scale for depression in dementia. Biol Psychiatry 1988;23:271 -284.

13. Camozzato $\mathrm{Al}$, Kochhann $\mathrm{R}$, Simeoni $\mathrm{C}$, et al. Reliability of the Brazilian Portuguese version of the Neuropsychiatric Inventory (NPI) for patients with Alzheimer's disease and their caregivers. Internat Psychogeriatr 2008;20:383-393.

14. Cummings JL, Mega M, Gray K, Rosenberg-Thompson S, Carusi DA, Gornbein J. The Neuropsychiatric Inventory: comprehensive assessment of psychopathology in dementia. Neurology 1994;44:2308-2314.

15. Pfeffer RI, Kurosaki TT, Harrah CH Jr, Chance JM, Filos S. Measurement of functional activities in older adults in the community. J Gerontol 1982;37:323-329.

16. Folstein MF, Folstein SE, McHugh PR. Mini-Mental State: a practical method for grading the cognitive state of patients for the clinician. J Psychiatr Res 1975;12:189-198.

17. Roth M, Tym E, Mountjoy CO, et al. CAMDEX: a standardized instrument for the diagnosis of mental disorder in the elderly with special reference to the early detection of dementia. Br J Psychiatry 1986;149:698-709.

18. Reitan RM. Validity of the trail making test as an indicator of organic brain damage. Percept Mot Skills 1958;8:271-276.

19. Porteus SD. New applications of the Porteus Maze tests. Percept Mot Skills 1968;26:787-798. 
20. Brucki SMD, Malheiros SMF, Okamoto IH, Bertolucci PHF. Dados normativos para o teste de fluência verbal categoria animais em nosso meio. Arq Neuropsiquiatr 1997;55:56-61.

21. Fazekas F, Chawluk JB, Alavi A, Hurtig HI, Zimmerman RA. MR signal abnormalities at $1.5 \mathrm{~T}$ in Alzheimer's dementia and normal aging. Am J Roentgenology 1987;149:351-356.

22. Peters N, Opherk C, Danek A, Ballard C, Herzog J, Dichgans $M$. The pattern of cognitive performance in CADASIL: a monogenic condition leading to subcortical ischemic vascular dementia. Am J Psychiatry 2005;162:2078-2085.

23. Boyle PA, Paul R, Moser D, Zawack T, Gordon N, Cohen R. Cognitive and neurologic predictors of functional Impairment in vascular dementia. Am J Geriatr Psychiatry 2003;11:103-106.

24. Mast BT, Yochim B, MacNeill SE, Lichtenberg PA. Risk factors for geriatric depression: the importance of executive functioning within the vascular depression hypothesis. J Gerontol A Biol Sci Med Sci 2004;59:1290-1294.

25. Soares JC, Mann JJ. The anatomy of mood disorders: review of structural neuroimaging studies. Biol Psychiatry 1997;41:86-106.

26. Lanna MEO, Moreira DM, Alves GS, Alves CEO, Valente LE, Laks J, Engelhardt E. Vascular dementia bythalamic strategic infarct. Arq Neuropsiquiatr 2008;66:412-414.

27. Fish M, Bayer A. Vascular subcortical syndrome of aging. Rev Clin Gerontol 2004;14:269-282.
28. Das RR, Seshadri S, Beiser AS, et al. Prevalence and correlates of silent cerebral infarcts in the Framingham offspring study. Stroke 2008;39:2929-2935.

29. Swartz RH, Sahlas DJ, Black SE. Strategic involvement of cholinergic pathways and executive dysfunction: does localization of white matter signal hyperintensities matter? J Stroke Cerebrovasc Dis 2003;12:29-36.

30. de Groot JC, de Leeuw F-E, Achten E, et al. Prevalence of cerebral white matter lesions in elderly people: a population based magnetic resonance imaging study. The Rotterdam Scan Study. J Neurol Neurosurg Psychiatry 2001;70:9-14.

31. Sachdev PS, Wen W, Christensen H, Jorm AF. White matter hyperintensities are related to physical disability and poor motor function. J Neurol Neurosurg Psychiatry 2005;76: 362-367.

32. Debette S, Bombois S, Bruandet A, et al. Subcortical hyperintensities are associated with cognitive decline in patients with mild cognitive impairment. Stroke 2007;38:2924-2930.

33. Bombois S, Debette S, Bruandet A, et al. Vascular subcortical hyperintensities predict conversion to vascular and mixed dementia in MCI patients. Stroke 2008;39:2046-2051.

34. Vataja R, Pohjasvaara T, Mantyla R, et al. MRI correlates of executive dysfunction in patients with ischaemic stroke. Eur J Neurol 2003;10:625-631. 